\begin{tabular}{ccc}
\hline International Journal of Engineering \& Technology, $7(4.35)(2018) 946-949$ \\
SPC \\
Website w ww. sciencepubco.com/index.php/IJET \\
Research paper
\end{tabular}

\title{
A Computational and Experimental Study of a Small-Scale Flat-Shaped Vertical Axis Wind Turbine
}

\author{
NF. Kadir ${ }^{1 *}$, H. Mohamed ${ }^{1}$, A. Manap ${ }^{2}$ \\ ${ }^{1}$ Department of Mechanical Engineering, College of Engineering, Universiti Tenaga Nasional, 43000 Kajang, Selangor, Malaysia \\ ${ }^{2}$ Institute of Power Engineering (IPE), Universiti Tenaga Nsional, 43000 Kajang, Selangor, Malaysia \\ *Corresponding author E-mail:Nurul.Fateha@uniten.edu.my
}

\begin{abstract}
This paper focuses on a computational and experimental study of flat-shaped turbine blades for a small scale Vertical Axis Wind Turbine (VAWT). In the computational analysis, a 2-Dimensional (2D) wind turbine model with three flat blades was designed using Ansys Fluent, which is computational fluid dynamics (CFD) software. The wind speed around the blades was simulated in a range of $3 \mathrm{~m} / \mathrm{s}$ to $8 \mathrm{~m} / \mathrm{s}$. Velocity and pressure distributions of the airflow around the blades were then observed. Pressures acting on the blades surface were then averaged and used to estimate the angular speed of the wind turbine model using the principles of torque and moment of inertia. A smallscale prototype was designed, fabricated and tested to validate the simulation result. Testing results show that the wind turbine prototype can rotate with an average speed of $148.8 \mathrm{rpm}$ when having a $3.27 \mathrm{~m} / \mathrm{s}$ wind speed. At the similar wind speed, the simulation result has estimated the angular speed to be $119 \mathrm{rpm}$. The percentage difference of the angular speed is about $20 \%$.
\end{abstract}

Keywords: Computational Fluid Dynamics (CFD); Flat-shaped, Small scale; Vertical Axis Wind Turbine (VAWT); Wind energy

\section{Introduction}

Renewable energy is energy generated from natural processes that are continually replenished, renewed and hardly exhausted such as sunlight, geothermal heat, wind, tides, water, and biomass. Wind, for example, has become an attractive source for renewable energy applications in many countries such as Denmark, Sweden, and China. Besides, wind energy contributes to diversifying sources of energy generation, which can decrease fuel import dependency and lead to sustainable energy growth. Wind energy is converted to mechanical motion and electricity when the wind blows over the front surface of a wind turbine blade. Currently, small-scale wind turbines have about 50-300 $\mathrm{W}$ of power output, which could be a reliable, clean energy harvester [1]. However, since the turbine is small in size, it can only work when any natural or humanmade obstacles do not obstruct an approaching wind. These obstacles will slow down the wind speed and cause higher turbulence, hence lowering the performance of the wind turbines [2]. Furthermore, a better turbine design is highly required to ensure the small turbine can operate reliably and efficiently at low speeds.

From the previous research work, numerical studies have been carried out to determine design parameters and to set up baseline design specifications. Ion Nila et al. have studied the small fixed pitch straight bladed vertical axis wind turbine (SB-VAWT), which is one of the simplest types of a wind turbine. This wind turbine accepts winds from any angle of directions and it is suitable for wind speeds around 3 to $6 \mathrm{~m} / \mathrm{s}$ [3]. A $1000 \mathrm{~W}$ helical vertical axis wind turbine was designed and analyzed by A. Dumitras$\mathrm{cu}$ et al. for Romanian regions to estimate the reliability function and hazard rate. This type of wind turbine is easy to mount on a rooftop and suitable for a small scale wind turbine application [4]. The low efficiency of Savonius vertical axis wind turbine leads to the experiment developed by Andre Alaimo et al. to identify and study factors affecting the performance such as the number of blades, interference of shaft and the shape of the rotor. The study concludes that a computational method can be a good alternative to analyze and evaluate the turbine blade design compared to an experimental method because it is less expensive and less time consuming [5].

This study further explores the development of Vertical Axis Wind Turbine (VAWT) blades for low wind speed environments using computational fluid dynamics simulation, which is later validated by an experimental test. The computational simulation investigates the effects of different wind speeds on a 2dimensional (2D) turbine blade model with three flat shaped blades to observe the airflow, velocity and pressure distributions around the blades. Based on the distributions, the angular speed of the blades is theoretically calculated. A prototype of the blades design is then built and tested to compare the angular speeds between the experiment and simulation.

\section{Computational modelling}

The following parameters were considered in this work.

$\mathrm{P}=\mathrm{F} / \mathrm{A}$

where pressure, $P$, can be related to the force, $F$, acting on the blade surface area, $A$. Equation 2 shows the formula for the moment of inertia, $I$, which is a measure of a rotor cylinder's resistance to a rotational movement change.

$\mathrm{I}=\mathrm{m} \mathrm{r}^{2}$

Another important parameter is torque, . It is the product of the perpendicular force, $F$, and the radius of the blade. 


$$
\tau=\mathrm{F} \mathrm{r}
$$

The torque can be associated with the moment of inertia and angu-lar speed, $\omega$. Equation 4 will be used to find the angular speed of the blades design.

$$
\tau=\mathrm{I} \omega
$$
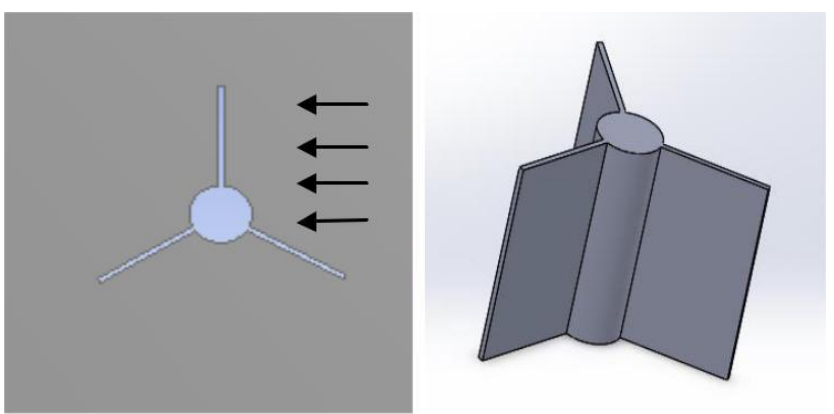

Fig. 1: (Left) The 2D model created in Ansys Fluent with the airflow coming from the right side. (Right) The 3D isometric view of the turbine model.

\subsection{CFD simulation set up and assumptions}

The CFD software used in this work is ANSYS Fluent. The blades design for the computational simulation was created based on the specification shown in Table 1. The design model is shown in Fig. 1. The airflow was set to come from the right side of the blades and incompressible. The turbulence airflow within boundary area was $0.42 \mathrm{~m} \mathrm{x} 0.42 \mathrm{~m}$ was observed. The fluid around the model was air with a constant density of $1.225 \mathrm{~kg} / \mathrm{m}^{3}$. The airflow was assumed to be in a steady state. Additionally, no friction effect (shear stress) was considered.

\section{Prototype design, fabrication and testing}

The prototype consists of four main parts, namely a bearing holder, a blade holder, three blades and a tower base as shown in Fig. 2 flow diagram. The bearing and blade holders were fabricated using 3D printing. The material used for both bearing and blade holders was acrylonitrile butadiene styrene (ABS) plastic because it has strong resistance to corrosive chemicals and physical impacts. While for the blade material, ABS plastic was selected because it is lightweight and robust. Polyvinyl chloride (PVC) plastic was used for the base. The blade holder and blades are made detachable as they can be easily dissembled or assembled from the bearing holder as shown in Fig. 3. This also enables the prototype to be easily fabricated and repaired from any defects. Since the primary concern of this work is the shape of the blade and its angular speed, the wind turbine prototype was not integrated with any motor or electronic components. To validate the computational results, the prototype was designed and fabricated based on the same specification in Table 1 .

Table 1: Turbine blade specifications

\begin{tabular}{|c|c|c|}
\hline No. & Design specification & Data \\
\hline 1. & Blade shape & Flat-shaped \\
2. & Blade number & 3 \\
3. & Blade radius & $0.21 \mathrm{~m}$ \\
4. & Blade length & $0.42 \mathrm{~m}$ \\
5. & Blade thickness & $0.0105 \mathrm{~m}$ \\
6. & Blade area & $0.35 \mathrm{~m}$ \\
7. & Overall configuration height & $0.35 \mathrm{~m} \mathrm{[7]}$ \\
8. & Rotor cylinder radius & $0.06 \mathrm{~m}$ \\
\hline
\end{tabular}
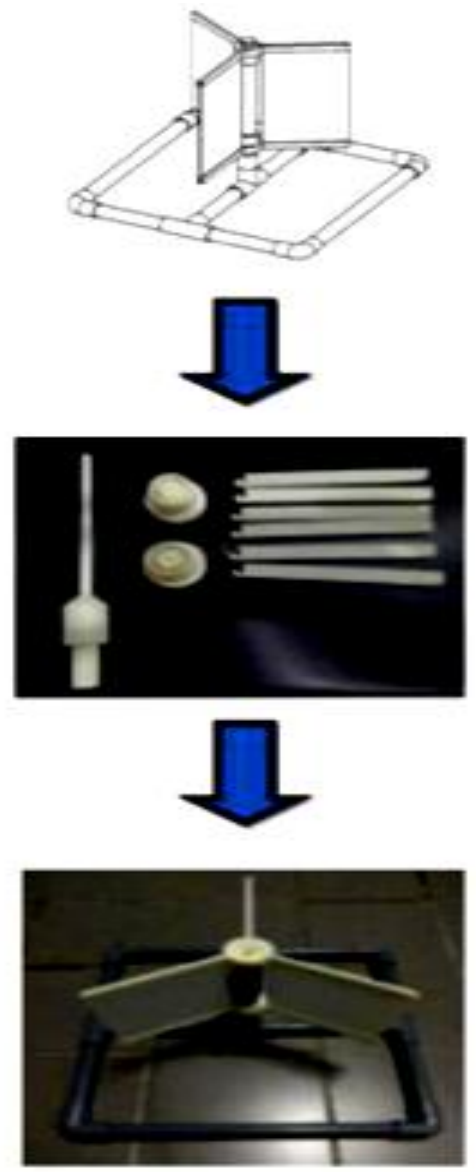

Fig. 2: Flow diagram for the design and fabrication process
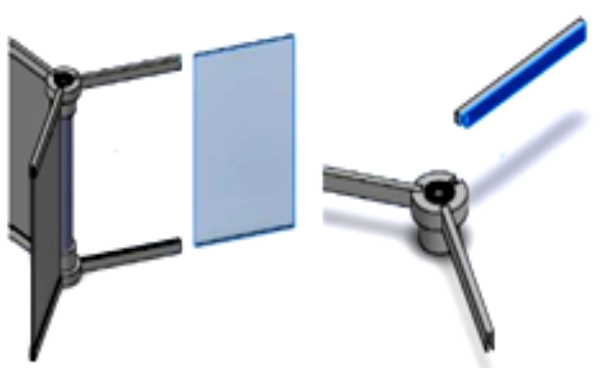

Fig. 3: The blade and bearing holders

After fabrication process was completed, the prototype was tested and placed in front of table fan with a recorded speed of $3.27 \mathrm{~m} / \mathrm{s}$. The fan wind speed was measured using a digi-tal anemometer. The angular speed of the prototype was measured in revolution per minute (rpm) using a tachometer.

\section{Results and Discussion}

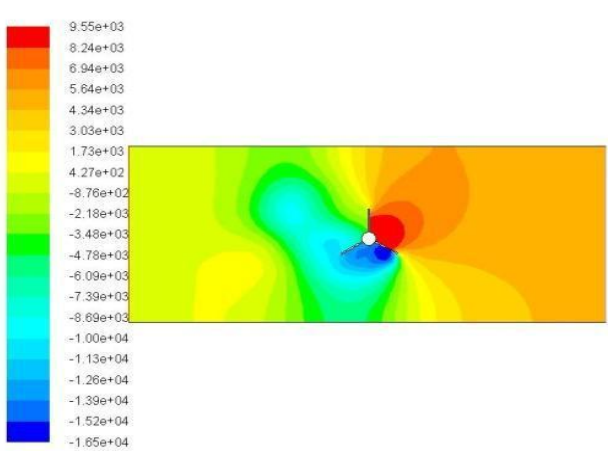




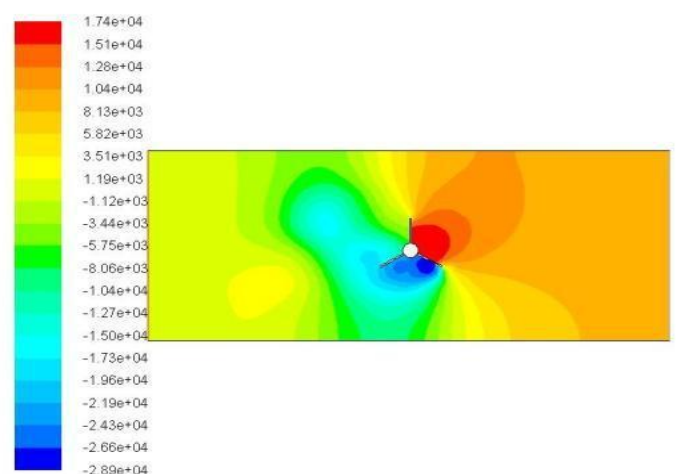

(b)

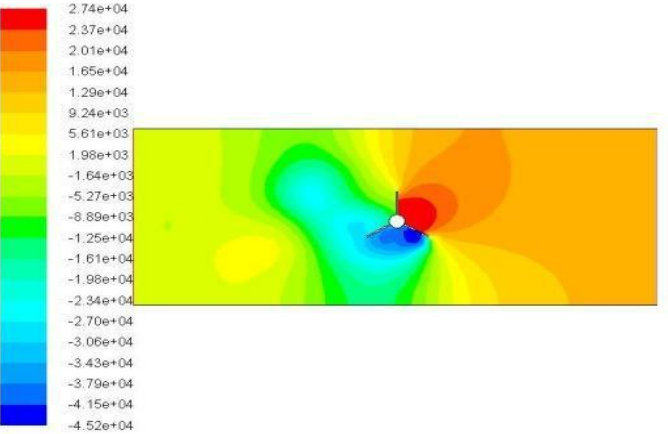

(c)

Fig. 4: Airflow simulation pressure results using Ansys Fluent software for (a) $3.0 \mathrm{~m} / \mathrm{s}$ (b) $4.0 \mathrm{~m} / \mathrm{s}$ (c) $5.0 \mathrm{~m} / \mathrm{s}$ wind speeds.

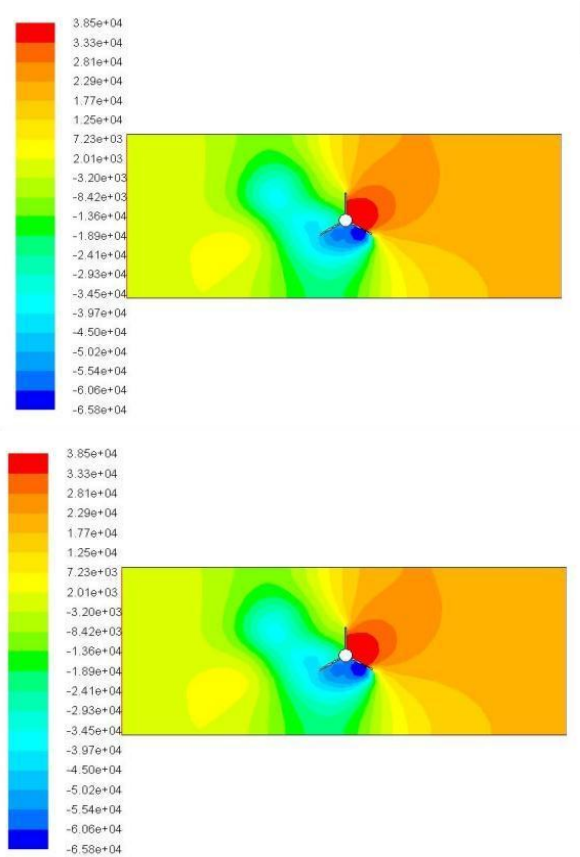

(a)

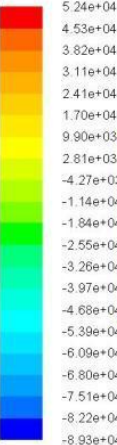

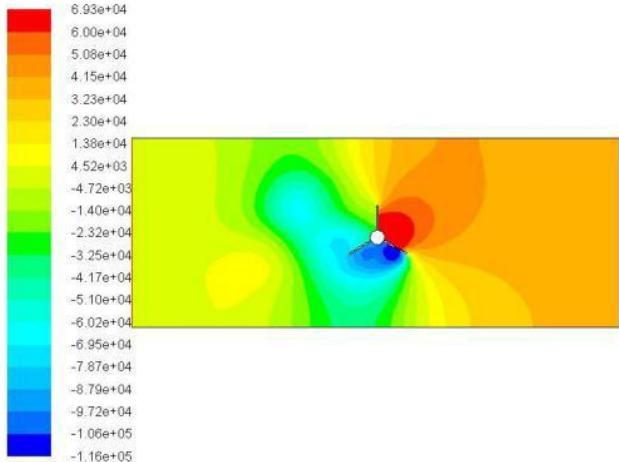

ANSYS

ANSYS Fig. 5: Airflow simulation pressure results using Ansys Fluent software for (a) $6.0 \mathrm{~m} / \mathrm{s}$ (b) $7.0 \mathrm{~m} / \mathrm{s}$ (c) $8.0 \mathrm{~m} / \mathrm{s}$ wind speeds.

Table 2: Flat-shaped turbine blades 2D model simulation computational results

\begin{tabular}{|c|c|c|c|c|}
\hline $\begin{array}{c}\text { Wind } \\
\text { speed } \\
(\mathrm{m} / \mathrm{s})\end{array}$ & $\begin{array}{c}\text { Average } \\
\text { pressure } \\
\text { distribution } \\
\text { in gauge } \\
\text { pressure } \\
(\mathrm{Pa})\end{array}$ & $\begin{array}{c}\text { Force } \\
(\mathrm{N})\end{array}$ & $\begin{array}{c}\text { Torque } \\
(\mathrm{Nm})\end{array}$ & $\begin{array}{c}\text { Angular } \\
\text { speed } \\
(\mathrm{rpm})\end{array}$ \\
\hline 3.0 & $\begin{array}{c} \\
4.55 \times 10^{3}\end{array}$ & 808.51 & 169.79 & \\
\hline .0 & $1.74 \times 10^{4}$ & $1,479.79$ & 69.19 & 113.42 \\
5.0 & $2.74 \times 10^{4}$ & 2330.79 & 489.35 & 217.93 \\
6.0 & $3.85 \times 10^{4}$ & 3274.25 & 687.59 & 306.21 \\
7.0 & $5.24 \times 10^{4}$ & 4456.38 & 935.84 & 416.76 \\
8.0 & $6.93 \times 10^{4}$ & 5893.64 & 1237.67 & 551.76 \\
\hline
\end{tabular}

Table 2 shows the calculated force, torque and angular speed based on the pressure distributions in Figs. 4 and 5. It can be seen that the angular speed increases when the wind speed increases. The reason is that higher wind speeds create high pressure around the blades. The relationship between wind speed and angular speed of the flat-shaped blades is depicted in Fig.6.

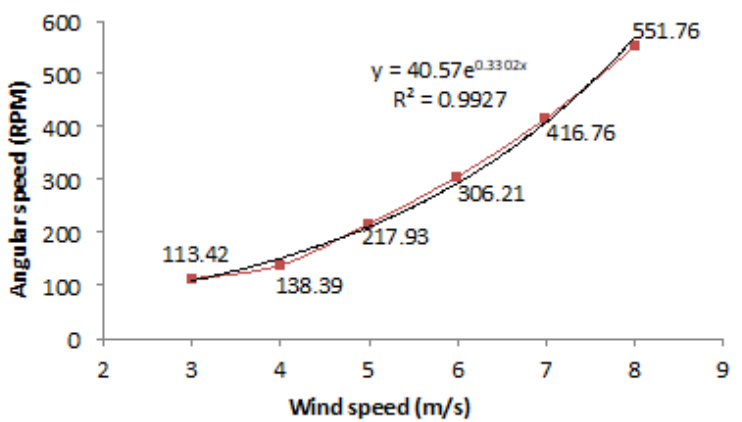

Fig.6: Graph of angular speed versus wind speed

The correlation (Equation 5) can be obtained from the angular and wind speeds relationship as presented in Fig. 6. The correlation can be used to predict the angular speed of the wind turbine model for any wind speeds.

$\mathrm{y}=40.57 e^{0.3302 \mathrm{x}}(\mathrm{rpm})$

Table 3: Prototype testing results

\begin{tabular}{|c|c|c|c|c|}
\hline $\begin{array}{c}\text { Measured wind } \\
\text { speed (m/s) }\end{array}$ & \multicolumn{4}{|c|}{ Blades angular speed (rpm) } \\
\cline { 2 - 5 } & Reading 1 & Reading 2 & Reading 3 & $\begin{array}{c}\text { Average } \\
\text { reading }\end{array}$ \\
\hline 3.27 & 146.7 & 152.3 & 147.5 & 148.8 \\
\hline
\end{tabular}

Table 3, on the other hand, shows the experimental values of angular speed versus the wind speed of the fan. The wind speed in 
the experiment was constant due to the limitation of the fan control system. The average angular speed was recorded to be around $148.8 \mathrm{rpm}$ at $3.27 \mathrm{~m} / \mathrm{s}$ wind speed. To compare the angular speed, from experimental and simulation result, Equation 5 was used to interpolate the computational angular speed at $3.27 \mathrm{~m} / \mathrm{s}$ wind speed. The estimated angular speed was $119.43 \mathrm{rpm}$. Using Equation 6 below, the percentage difference was estimated to be $20 \%$,

$\omega_{\text {experimental }}-\omega_{\text {simulation/ }} \omega_{\text {experimental x }} 100 \%$

This percentage difference is relatively reasonable considering shear stress effect (friction) in the simulation was assumed negligible. Furthermore, the simulation was carried out only for the simple 2D model. A previous study by Wenehenubun et al. [14] has also achieved a comparable angular speed that is around 120 to $400 \mathrm{rpm}$ for small vertical axis wind turbines.

\section{Conclusion}

In summary, the computational analysis has successfully predicted the performance of the actual prototype. Both experimental and simulation angular speeds are found suitable to be applied in low wind speed environments and agree with other previous studies [14-16] for a small vertical axis wind turbine. The simulation re-sult, however, underestimates the prototype angular speed with a percentage difference of around $20 \%$. This underestimation is reasonable because few simplifications were made during the simulation. It is highly recommended to design and analyze a 3D model of the blades to improve the computational analysis. Addi-tionally, the shear stress effect (friction) needs to be considered for future work. Above all, this study is very beneficial as it offers one of the practical and cost-efficient methods that can be used to design and analyze advanced turbine blades of a small-scale wind turbine.

\section{Acknowledgement}

Universiti Tenaga Nasional supported this study under the UNITEN Start-Up Grant BOLD 2025, project code RJO10289176/B/1/2017/20.

\section{References}

[1] A. Celik, "Energy output estimation for small-scale wind power generators using Weibull-representative wind data," Journal of Wind Engineering and Industrial Aerodynamics, vol. 91, no. 5, pp. 693-707, 2003

[2] K. G. Gebrelibanos, "Feasibility Study of Small Scale Standalone Wind Turbine for Urban Area: Case study: KTH Main Campus,"

[3] 2013.

[4] N. Ion, B. Radu, and S. Marcel, "Small power wind turbine (Type DARRIEUS),” Incas Bull., vol. 4, no. 1, pp. 135-142, 2012.

[5] A. Dumitrascu, B. Lepadatescu, D. Dumitrascu, A. Nedelcu, and D.

[6] V. Ciobanu, "Reliability Estimation of Parameters of Helical Wind Turbine with Vertical Axis," Sci. World J., vol. 2015, 2014.

[7] A. Alaimo, A. Esposito, A. Messineo, C. Orlando, and D. Tumino,

[8] “3D CFD analysis of a vertical axis wind turbine," Energies, vol. 8, no. 4, pp. 3013-3033, 2015.

[9] C. Torasa and N. Sermsri, "The Application of Roof Ventilator for Electricity Generation,” Procedia - Soc. Behav. Sci., vol. 197, no. February, pp. 1690-1696, 2015.

[10] C. Torasa and N. Sermsri, "The Application of Roof Ventilator for Electricity Generation," Procedia - Soc. Behav. Sci., vol. 197, no. February, pp. 1690-1696, 2015.

[11] New Straits Times, "Making Good Use of Our Abundant Resource," p. 7.]

[12] "Small Scale Vertical Axis Portable Wind Turbine for Charging Electronic Gadget," International Journal of Engineering Research \& Technology (IJERT), vol. 4, no. 2, pp. 638-641, 2015.
[13] M. Latif, M. Muharam, and Y. Puriza, "Simple Hawt Prototype Efficiency at Small Scale Wind," vol. 12, no. 3, pp. 549-556, 2014.

[14] K. Babu, N. Raju, M. Reddy and D. Rao, "The Material Selec-tion For Typical Wind Turbine Blades Using A Madm Approach\& Analysis Of Blades," pp. 1-12, 2006.

[15] I. Al-Bahadly, "Building a wind turbine for rural home," Energy for Sustainable Development, vol. 13, no. 3, pp. 159-165, 2009.

[16] Monolithic Dome Institute, "Radius of Curvature.” [Online]. Avail-

[17] able:http://www.monolithic.org/blogs/engineering/radius-of-

[18] curvature/photos. [Accessed: 24-Nov-2016].

[19] F. Wenehenubun, A. Saputra and H. Sutanto, "An Experimental Study on the Performance of Savonius Wind Turbines Related With the Number of Blades," Energy Procedia, vol. 68, pp. 297-304, 2015.

[20] "Vertical Axis Wind Turbines," 2017. [Online]. Available: http://mragheb.com/NPRE\%20475\%20Wind\%20Power\%20System s/Vertical\%20Axis\%20Wind\%20Turbines.pdf. last visit 01.02.2017.

[21] W. A.C., H. SIHOMBING and Y. M.Y, "Design and Analysis of

[22] 5kW Savonius Rotor Blade", Global Engineers \& Technologist S Review, pp. 1-8, 2012. 